\title{
Corrigendum
}

\section{Serotonin Transporter Polymorphism Mediates Vulnerability to Loss of Incentive Motivation Following Acute Tryptophan Depletion}

\author{
Jonathan P Roiser ${ }^{1,2}$, Andrew D Blackwell', Roshan Cools ${ }^{3,4}$, Luke Clark ${ }^{4}$, David C Rubinsztein ${ }^{5}$, \\ Trevor W Robbins ${ }^{4}$ and Barbara J Sahakian' \\ 'Department of Psychiatry, Addenbrooke's Hospital, Cambridge, UK; ² Department of Imaging Neuroscience, Institute of Neurology, London, UK; \\ ${ }^{3}$ Helen Wills Neuroscience Institute, University of California, Berkeley, CA, USA; ${ }^{4}$ Department of Experimental Psychology, Downing Street, \\ Cambridge, UK; ${ }^{5}$ Department of Medical Genetics, Cambridge Institute for Medical Research, Addenbrooke's Hospital, Cambridge, UK
}

Neuropsychopharmacology (2006) 3 I, 2273. doi:I 0.I 038/sj.npp. I 301084

Correction to: Neuropsychopharmacology (2006) 31, 2264-2272. doi:10.1038/sj.npp.1301055

Following the publication of this article, the authors noted that the fourth author affiliation was wrong.
The complete and correct author affiliations are above. 